\title{
Oxytocin: an unexpected risk for cardiologic and broncho-obstructive effects, and allergic reactions in susceptible delivering women
}

Gennaro Liccardi ${ }^{1 *}$, Maria Beatrice Bilò ${ }^{2}$, Ciro Mauro ${ }^{3}$, Antonello Salzillo ${ }^{1}$, Amedeo Piccolo ${ }^{1}$, Maria D’Amato ${ }^{4}$, Annabella Liccardi ${ }^{1}$ and Gennaro D'Amato ${ }^{1}$

\begin{abstract}
Oxytocin (Sintocynon) is considered an uncommon cause of severe allergic reactions during delivery. We have recently shown that allergic sensitization to latex might constitute an important predisposing risk factor for anaphylaxis after the first infusion of oxytocin during delivery.

Some oxytocin cardiovascular activities such as lowering blood pressure, negative cardiac inotropy and cronotropy, parasympathetic neuromodulation, vasodilatation etc. can induce significant side effects mimicking cardiac anaphylaxis, and constitute an additional differential diagnostic problem in delivering women with suspected or real allergic background. Finally, some ex vivo models have shown that oxytocin, under pro-inflammatory cytokines stimulation, such as those occurring in asthma, may induce contraction of smooth muscle and airway narrowing.

This background suggests that allergic sensitization to latex allergens constitutes a significant but underestimated risk factor for triggering severe systemic reactions after the infusion of oxytocin and, consequently, there is a need of particular attention in managing delivering women suffering from latex allergy and bronchial asthma. An accurate anamnestic, clinical and diagnostic evaluation, latex-free anesthesiological setting, use of oxytocin-alternative agents and, if necessary, a drug premedication are likely to reduce the risk of anaphylactic/broncho-obstructive reactions in these women.
\end{abstract}

Keywords: Anaphylaxis, Bronchial asthma, Delivery, Drug allergy, Heart, Hypersensitivity, Latex allergy, Oxytocin, Oxytocin allergy, Oxytocin and heart, Oxytocin side effects

\section{Background and Main text}

Oxytocin (Sintocynon) is usually considered an uncommon cause of severe allergic reactions during delivery. Very few documented reports on anaphylactic/anaphylactoid reactions as well as severe airway obstruction have been published [1-6]. However, some experimental data highlight the possibility that the risk of developing severe systemic reactions after the infusion of oxytocin during delivery could be higher than expected in some allergic women. In this context, allergic sensitization to latex, the second most frequently incriminated substance inducing anaphylaxis during anesthesia [7], which is also a relatively common condition in female sex [8], might represent an important predisposing risk factor. It is important to outline that hypersensitivity reactions in anesthesia setting are significantly higher in adult women than in men [9]; moreover, Draisci et al. [10] reported a higher prevalence of latex sensitization in the obstetric population than in non-pregnant subjects undergoing gynaecologic surgery.

Ogata and Minami [11] demonstrated homology in the protein sequence of oxytocin and latex allergens $\mathrm{Hev} b$ 7.01 and Hev b 7.02 (patatin). These authors suggested that, in their patient sensitized to patatin, subsequent administration of oxytocin could facilitate the antigen recognition, resulting in an anaphylactic response to latex.

\footnotetext{
* Correspondence: gennaro.liccardi@tin.it

'Department of Chest Diseases, Division of Pneumology and Allergology.

High Speciality "A.Cardarelli" Hospital, Naples, Italy

Full list of author information is available at the end of the article
} 
We have recently described two life-threatening anaphylactic reactions with onset a few minutes after the infusion of oxytocin in two women sensitized to latex allergens [12]. Both reactions occurred during caesarian section under spinal anaesthesia in the delivery room of our Hospital.

Diagnostic procedures confirmed an IgE - mediated allergic response to both latex and oxytocin, no allergic response was found to other agents used before or during caesarian section such as local antiseptics, proton-pump inhibitors, antihypertensive drugs, low molecular weight heparin (enoxaparin sodium), human albumin.

In view of the few data available in literature, we believe that this topic is underestimated because such adverse events might be easily attributed to latex allergy or to usual "side effects" or alternative/unknown causes. Moreover, this risk could be underestimated if we consider that female sex shows higher prevalence of both hypersensitivity reactions in the anesthesia setting and latex allergy than men.

Among the possible "side effects", it is important to outline the role of oxytocin on heart [13].

It has been shown that both oxytocin and its receptors are found in the heart and large vessels [14], where accumulating evidence demonstrates cardio protective effects such as natriuresis, altered insulin liberation and antidiabetic actions, antioxidant actions, inhibition of inflammation, stimulation of endothelial markers in mesenchymal cells and stem cells [15-18].

However, several other cardiovascular activities such as lowering blood pressure, negative cardiac inotropy and cronotropy, parasympathetic neuromodulation, vasodilatation etc. which may be beneficial in some clinical conditions, can induce significant side effects during delivery
[13]. These side effects mimicking cardiac anaphylaxis represent an additional differential diagnostic problem in delivering women with suspected or real allergic background [19] (Figure 1). In this context it is important to outline the necessity of serum tryptase determination to confirm the diagnosis of anaphylaxis.

Oxytocin induces uterine contractions during delivery and milk ejection during lactation through activation of a specific G protein-coupled receptor [20]. The expression of this receptor increases before the onset of labour highlighting uterine muscle sensitivity and promoting myometrial shortening.

Interestingly, it has been shown that the expression of oxytocin receptors plays a role not only in uterine but also in other human tissues such as kidney, ovary, heart, vascular endothelium etc. Labour and inflammation increase the expression of oxytocin receptors in human amnion [21], inflammatory conditions may also increase the production of oxytocin receptors in cultivated primary uterine smooth muscle cells [22].

Recently oxytocin receptors have been found also in human airway smooth muscle [23]. Moreover, Amrani et al. [24] have shown that asthma-related cytokines (IL13 and TNF alpha) modulate the expression of oxytocin receptors in human airway smooth muscle function suggesting a potential role of inflammation-induced changes in oxytocin receptor signaling in the regulation of airway hyper-responsiveness in asthma. In other words, in this ex vivo model, oxytocin, under pro-inflammatory cytokines stimulation, may induce contraction of smooth muscle and airway narrowing suggesting that oxytocin serves as a bronchoconstrictor [24]. As a confirmation of this possibility, a case of exclusive severe airway

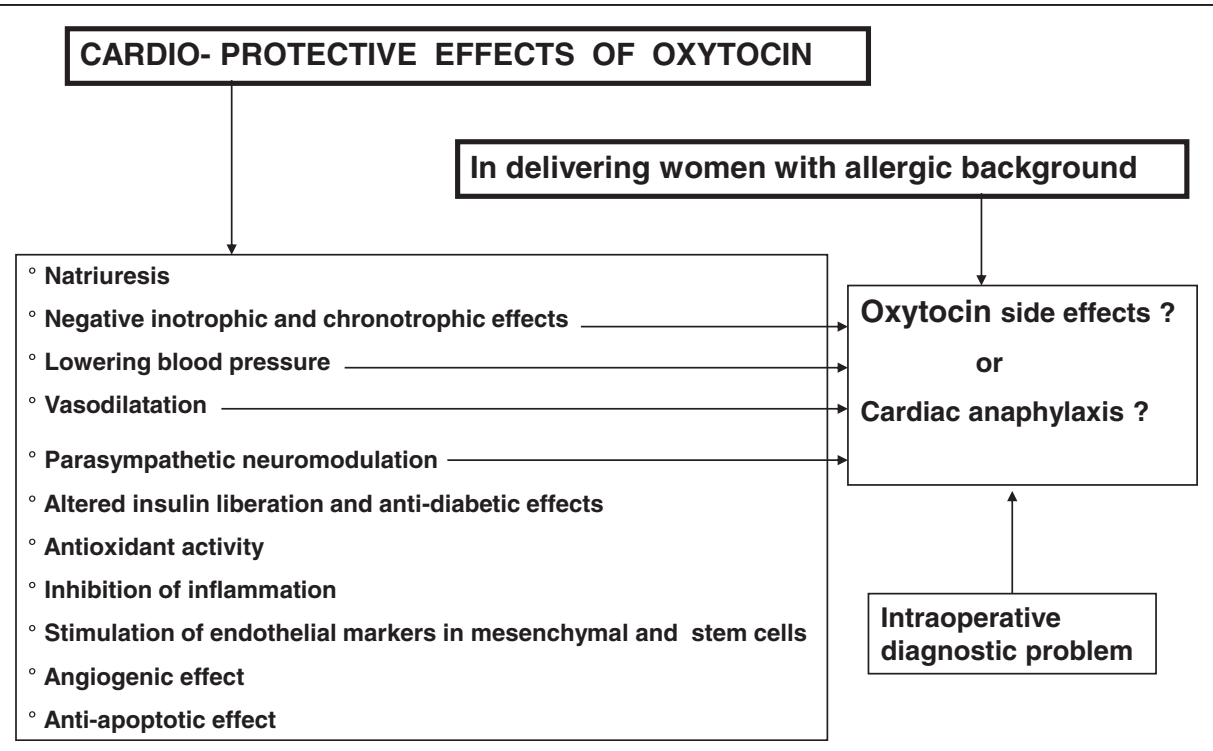

Figure 1 Cardio protection and anaphylactic-like effects of oxytocin. 
involvement (bronchospasm and laryngeal stridor) after oxytocin administration has also been reported [25].

Taken together, these data suggest that inflammatory conditions of airways such as those found in asthmatic women might constitute an independent (from anaphylaxis) risk factor for airway obstruction after infusion of oxytocin during delivery. The role of oxytocin receptors could also explain the well known worsening of asthma control in about one-third of pregnant women suffering from asthma [26-28].

Finally, Gonzalez-Perez et al. have shown that women suffering from severe asthma are at higher risk of anaphylaxis than men [29], as a consequence the risk of developing anaphylaxis, asthma exacerbation or both is likely high in severe asthmatic women (Figure 2).

Since oxytocin causes the alveoli in the breasts to contract causing milk let-down as the milk ejection reflex, there is some controversy over whether or not a woman can be "allergic to breastfeeding". In fact there are women who have allergy-like symptoms associated with the milk ejection reflex during breastfeeding. These symptoms can include itching, redness, rash or hives on the trunk, arms or legs, anaphylactic reactions as they have been also shown [30]. It has been suggested that these symptoms can also represent adverse reactions to the synthetic forms of oxytocin. Systemic reactions to preservatives contained in preparations of oxytocin has been also described [31].

Although in vivo tests with oxytocin have not been standardized, a diluted/undiluted oxytocin solution should be used by skin prick test/intradermal test. In our case report, both patients reacted after the use of skin prick test and, consequently, intradermal test was not necessary [12]. Latex hypersensitivity should be excluded by using in vivo (skin prick tests) and in vitro (evaluation of specific IgE antibodies by classic or, if possible, micro-array technique) tests.

\section{Conclusions}

In conclusion, our findings suggest a particular attention in managing delivering women suffering from latex allergy and bronchial asthma. An accurate anamnestic, clinical and diagnostic evaluation, latex-free anesthesiological setting, use of oxytocin-alternative agents and, if suffering from asthma, a drug premedication [32] are likely to reduce the risk of anaphylactic or airway-obstructive reactions in these women.

Further in vitro studies are necessary to establish the occurrence of an immunological cross-reaction between latex and oxytocin as well as the role of oxytocin and its receptors in heart and airway. Finally, further clinical studies should be designed to a better understanding/management of respiratory and cardiac effects of oxytocin administration.

\section{Summary statement}

Oxytocin may constitute a risk factor for anaphylaxis, bronchial asthma and cardiologic side effects in delivering women.

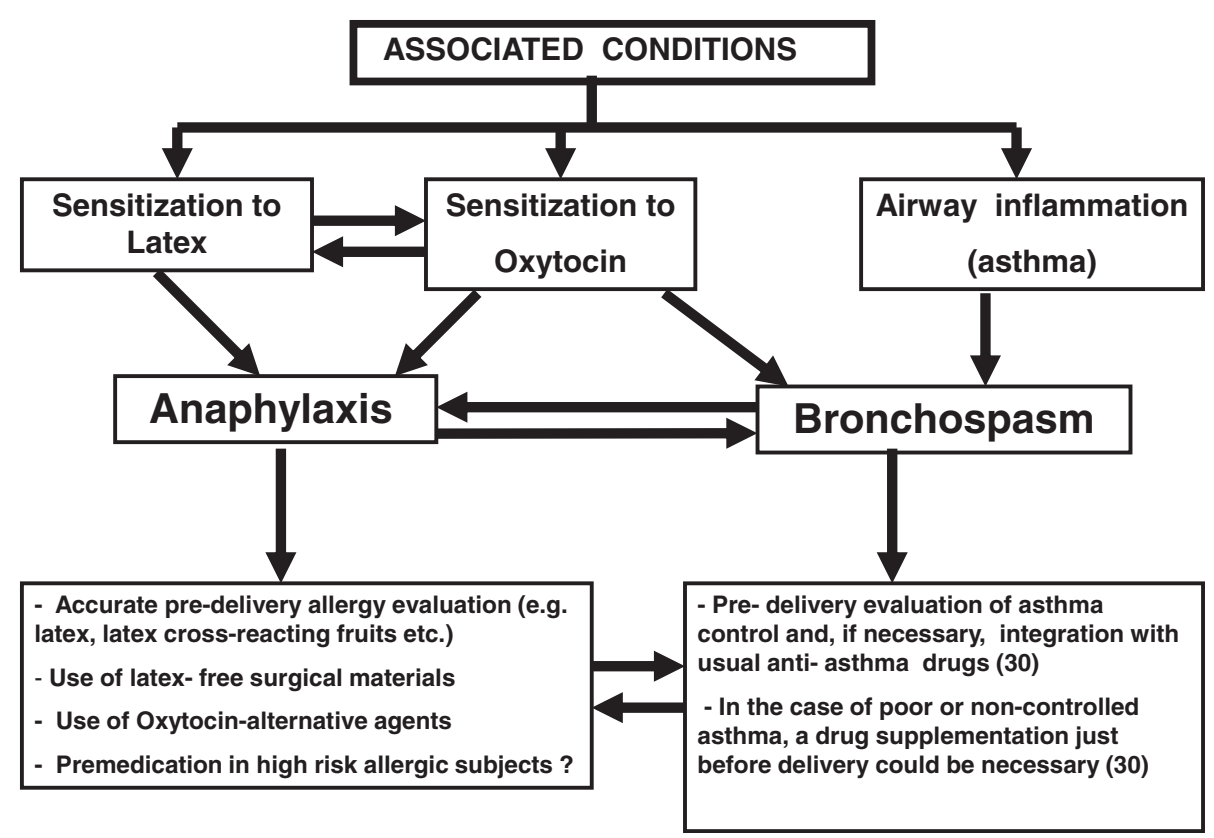

Figure 2 Suggested correlation between latex, oxytocin sensitization and airway inflammatory conditions. 


\section{Competing interest}

All authors declare that they have no conflict of interest and that the study has been carried out without any financial support.

\section{Author details}

'Department of Chest Diseases, Division of Pneumology and Allergology. High Speciality "A.Cardarelli" Hospital, Naples, Italy. ${ }^{2}$ Allergy Unit, Department of Immunology, Allergy and Respiratory Diseases, University Hospital, Ancona, Italy. ${ }^{3}$ Division of Cardiology, Cardiac Intensive Care and Hemodynamic. Department of Intensive Care, High Speciality "A.Cardarelli" Hospital, Naples, Italy. ${ }^{4}$ Department of Respiratory Disease, University

"Federico II" University - AO "Dei Colli", Naples, Italy.

Received: 24 June 2013 Accepted: 25 September 2013

Published: 20 October 2013

\section{References}

1. Lin MC, Hsieh TK, Liu CA, Chu CC, Chen JY, Wang JJ, Shieh JP: Anaphylactoid shock induced by oxytocin administration- a case report. Acta Anaesthesiol Taiwan 2007, 45:233-236.

2. Shimo T, Nishiite S, Masuoka M, Seki S, Tsuchida H: Intraoperative anaphylactic shock induced by methylergometrine and oxytocin. Masui 2006, 55:447-450.

3. Spears FD, Liu DW: Anaphylactoid reaction to syntocinon? Anaesthesia 1994, 49:41-43.

4. Morriss WW, Lavies NG, Anderson SK, Southgate HJ: Acute respiratory distress during caesarean section under spinal anaesthesia. A probable case of anaphylactoid reaction to Syntocinon. Anaesthesia 1994, 49:41-43.

5. Maycock EJ, Russell WC: Anaphylactoid reaction to Syntocinon. Anaesth Intensive Care 1993, 21:211-212.

6. Marmo D, Sacerdoti C, Di Minno RM, Guarino I, Villani R, Di lorio C Anaphylactic shock during hyperbaric oxygen therapy. Undersea Hyperb Med 2012, 39:613-18.

7. Mertes PM, Alla F, Trechot P, Auroy Y, Jougla E: Anaphylaxis during anesthesia in France: a 8-year national survey. J Allergy Clin Immunol 2011, 128:366-73

8. Lieberman P: Anaphylactic reactions during surgical and medical procedures. J Allergy Clin Immunol 2002, 110:S64-S69.

9. Mertes PM, Demoly P, Malinovsky JM: Hypersensitivity reactions in the anesthesia setting/allergic reactions. Curr Opin Allergy Clin Immunol 2012, 12:361-368.

10. Draisci G, Zanfini BA, Nucera E, Catarci S, Sangregorio R, Schiavino D, Mannocci A, Patriarca G: Latex sensitization. A special risk for the obstetric population? Anesthesiology 2011, 114:565-569.

11. Ogata J, Minami K: Synthetic oxytocin and latex allergy. Br J Anaesth 2007, 98:845-846.

12. Liccardi G, Bilò M, Mauro C, Salzillo A, Piccolo A, D'Amato M, D'Amato G: Oxytocin: a likely underestimated risk for anaphylactic reactions in delivering women sensitized to latex. Ann Allergy Asthma Immunol 2013, 110:465-466.

13. Gutkowska J, Jankowski M: Oxytocin revisited: its role in cardiovascular regulation. J Neuroendocrinol 2012, 24:599-608.

14. Jankowski M, Wang D, Haijar F, Mukaddam-Daher S, Hoffman G, McCann SM, Gutkowska J: Oxytocin and its receptors are synthesized in the rat vasculation. Proc Natl Acad Sci USA 2000, 97:6207-6211.

15. Soares TJ, Coimbra TM, Martius AR, Pereira AG, Camio EC, Branco LG, Albuquerque-Aranjo WI, De Nucci G, Favaretto AL, Gutkowska J, McCann SM, Antunes-Rodrigues J: Atrial natriuretic peptide and oxytocin induce natriuresis by release of cGMP. Proc Natl Acad Sci USA 1999, 96:278-283.

16. Florian M, Jankowski M, Jankowski M: Oxytocin increases glucose uptake in neonatal rat cardiomyocytes. Endocrinology 2010, 151:482-491.

17. Iseri SO, Sener G, Saglan B, Gedik N, Ercan F, Yegen BC: Oxytocin ameliorates oxidative colonic inflammation by a neutrophil-dependent mechanism. Peptides 2005, 26:483-491.

18. Kim YS, Kwon JS, Hong MH, Kim J, Song CH, Jeon MH, Cho JG, Park JC, Kang JC, Ahn Y: Promigratory activity of oxytocin in umbilical cord bloodderived mesenchymal stem cells. Artif Organs 2010, 34:453-461.

19. Triggiani M, Patella V, Staiano Rl, Granata F, Marone G: Allergy and cardiovascular system. Clin Exp Immunol 2008, 153(Suppl 1):7-11.

20. Gimpl G, Fahrenholz F: The oxytocin receptor system: structure, function and regulation. Physiol Rev 2001, 81:629-683.
21. Terzidou V, Blanks AM, Kim SH, Thornton S, Bunnett PR: Labor and inflammation increase the expression of oxytocin receptor in human amnion. Biol Reprod 2011, 84:546-552.

22. Helmer $\mathrm{H}$, Tretzmuller $\mathrm{U}$, Brunbauer $\mathrm{M}$, Kaider $\mathrm{A}$, Husslein $\mathrm{P}$, Knofler $\mathrm{M}$ : Production of oxytocin receptor and cytokines in primary uterine smooth muscle cells cultivated under inflammatory conditions. J Soc Gynecol Investig 2002, 9:15-21.

23. Pequeux C, Breton C, Hagelstein MT, Geenen V, Legros JT: Oxytocin receptor pattern of expression in primary lung cancer and in normal human lung. Lung Cancer 2005, 50:177-188.

24. Amrani Y, Syed F, Huang C, Li K, Liu V, Jain D, Keslacy S, Sims MW, Baidouri H, Cooper PR, Zhao H, Siddiqui S, Brightling CE, Griswold D, Li L, Panettieri RS Jr: Expression and activation of the oxytocin receptor in airway smooth muscle cells: Regulation by TNFalpha and IL-13. Respir Res 2010, 11:104.

25. Cabestrero D, Perez-Paredes C, Femandez-Cid R, Arribas MA: Bronchospasm and laryngeal stridor as an adverse effect of oxytocin treatment. Crit Care 2003, 7:392

26. Liccardi G, Cazzola M, Canonica GW, D'Amato M, D'Amato G, Passalacqua G: General strategy for the management of bronchial asthma in pregnancy. Respir Med 2003, 97:778-789.

27. Namazy JA, Schatz M: Asthma and pregnancy. J Allergy Clin Immunol 2011, 128:1384-1385

28. McCallister JW: Asthma in pregnancy: management strategies. Curr Opin Pulm Med 2013, 19:13-17.

29. Gonzalez-Perez A, Aponte Z, Fernandez Vidaurre C, Garcia Rodriguez LA: Anaphylaxis epidemiology in patients with and without asthma: a United Kingdom database review. J Allergy Clin Immunol 2010, 125:1098-1104.

30. Shank JJ, Olney SC, McNamara MF: Recurrent postpartum anaphylaxis with breast-feeding. Obstet Gynecol 2009, 114:415-416.

31. Hofman H, Goerz G, Plewig G: Anaphylactic shock from chlorobutanolpreserved oxytocin. Contact Dermatitis 1986, 15:241.

32. Liccardi G, Salzillo A, Sofia M, D'Amato M, D'Amato G: Bronchial asthma. Curr Opin Anesthesiol 2012, 25:30-37.

doi:10.1186/2049-6958-8-67

Cite this article as: Liccardi et al:: Oxytocin: an unexpected risk for cardiologic and broncho-obstructive effects, and allergic reactions in susceptible delivering women. Multidisciplinary Respiratory Medicine 2013 8:67.

\section{Submit your next manuscript to BioMed Central and take full advantage of:}

- Convenient online submission

- Thorough peer review

- No space constraints or color figure charges

- Immediate publication on acceptance

- Inclusion in PubMed, CAS, Scopus and Google Scholar

- Research which is freely available for redistribution 